\title{
Moisture transfer in outer walls with layers of different density
}

\author{
Andrey Rymarov ${ }^{1 *}$, Dmitriy Titkov ${ }^{1}$, and Aleksey Ananiev ${ }^{2}$ \\ ${ }^{1}$ National Research Moscow State University of Civil Engineering, 129337, Moscow, Yaroslavskoe \\ highway, 26, Russia \\ ${ }^{2}$ Institution Research Institute of Building Physics of the Russian Academy of Architecture and \\ Building Sciences, 127238, Moscow, Lokomotivny driveway, 21, Russia
}

\begin{abstract}
The need to protect external walls from excess moisture to improve heat-shielding properties is an urgent task. If the outer wall is created from expanded clay concrete blocks, then the most interesting are the blocks created by layer-by-layer moulding, in which each layer can have its own given density. In such blocks, each layer has its own coefficients of thermal conductivity and vapor permeability, which allows you to select the required heat transfer resistance and vapor permeability of the outer wall for a specific region, taking into account the characteristics of the climate. The ability to have external walls with different material densities inside makes it possible to implement energy saving tasks in the building. The article discusses options for external walls made of expanded clay concrete blocks with layers with different densities and coefficients of thermal conductivity and vapor permeability. Changing the location of layers with different densities inside the blocks changes the local values of the vapor permeability resistance, which leads to a different nature of the movement of water vapor inside the wall in winter. It is good when water vapor does not accumulate in the wall; it does not condense and freely goes into the external environment. A dry wall is more durable, it loses less heat in winter. Changes in partial pressures at full saturation and with existing humidity inside the expanded clay concrete block for layers of different densities in winter are considered to determine the possible condensation from water vapor inside the wall. Layer-by-layer moulding of building materials improves their properties to increase resistance to heat transfer and to form a dry and more durable outer wall.
\end{abstract}

\section{Introduction}

Cellular concretes, which were well studied earlier, are now used less often due to the growing requirements for the thermal protection of buildings to solve energy-saving problems. New properties of expanded clay concrete blocks appear during layer-by-layer moulding [1], when the layers of the material have different densities and, accordingly, different values of the coefficients of thermal conductivity and vapour permeability. Reducing the flow of moisture through expanded clay concrete blocks with layers of different

\footnotetext{
$\overline{\text { * Corresponding author: rymarov@list.ru }}$
} 
densities during operation increases the resistance to heat transfer and allows you to save heat energy by reducing heat losses of the building in the winter season. As well as monitoring the resistance to vapour penetration, it will allow the outer wall to be kept in a dry state, which will increase its durability.

\section{Problem statement}

In the cold season, moisture moves from the room through the outer wall to the outside air, so when forming expanded clay concrete blocks in layers, it is useful to have denser layers closer to the inner surface of the wall. This approach will allow the water vapor located in the internal air not to enter the wall, which becomes dry in the winter season and more durable. And also at the same time, the resistance to moisture transfer and heat transfer of the wall increases, which reduces heat losses in the winter time by the premises of the building.

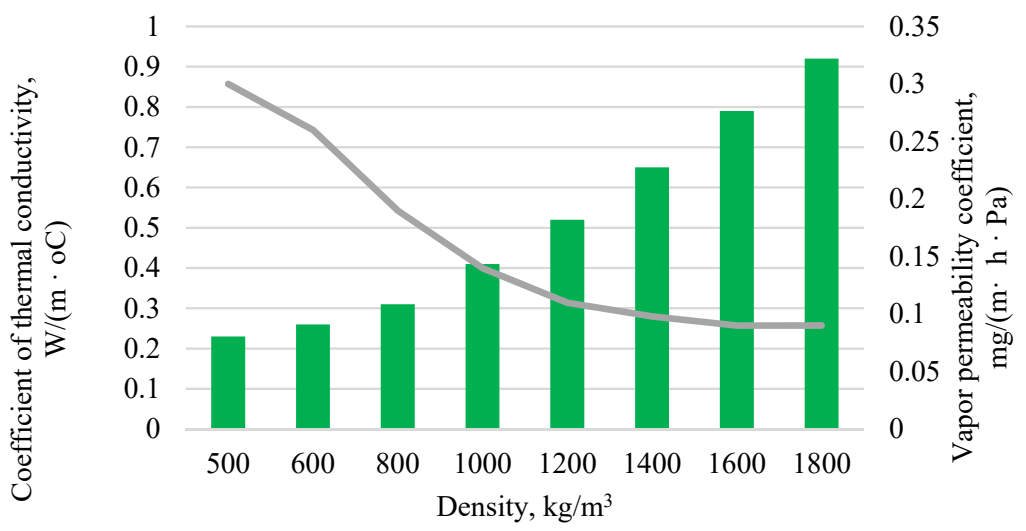

Coefficient of thermal conductivity $\longrightarrow$ Vapor permeability coefficient

Fig. 1. Change in the coefficients of thermal conductivity and vapor permeability depending on the density of expanded clay concrete.

The dependence of the thermal conductivity coefficient and the vapor permeability coefficient of aerated concrete with a material moisture content of about $10 \%$ of the density is nonlinear (Fig. 1), which is associated with the presence of solid elements of expanded clay concrete and air between them [2]. Studies of changes in temperature, partial pressures at full saturation and at the existing humidity inside the expanded clay concrete block on expanded clay sand in the outer wall at an outdoor air temperature of $-8.7^{\circ} \mathrm{C}$ and a relative humidity of $83 \%$ and an indoor air temperature of $+20^{\circ} \mathrm{C}$ and a relative humidity of $55 \%$. The calculations were carried out for the climatic conditions of the city of Moscow. Moisture transfer through building materials takes about a month, so the estimated outside air temperature is taken as the average for the coldest month, and for the city of Moscow it is January. The number of layers with which the blocks are formed is 7 , each layer has a thickness of $0.07 \mathrm{~m}$. If necessary, the thickness of the layers can be formed differently. The total thickness of the block is $0.49 \mathrm{~m}$. The ability of expanded clay concrete to absorb moisture depends on its density [3]. 6 variants of expanded clay concrete blocks with different layering of layers with different material density inside are considered. The first 
version of the wall consists of seven layers with a density of $1000 \mathrm{~kg} / \mathrm{m}^{3}, 600 \mathrm{~kg} / \mathrm{m}^{3}, 500$ $\mathrm{kg} / \mathrm{m}^{3}, 500 \mathrm{~kg} / \mathrm{m}^{3}, 600 \mathrm{~kg} / \mathrm{m}^{3}, 800 \mathrm{~kg} / \mathrm{m}^{3}, 1000 \mathrm{~kg} / \mathrm{m}^{3}$. The second version of the wall consists of seven layers with a density of $500 \mathrm{~kg} / \mathrm{m}^{3}, 500 \mathrm{~kg} / \mathrm{m}^{3}, 500 \mathrm{~kg} / \mathrm{m}^{3}, 600 \mathrm{~kg} / \mathrm{m}^{3}$, $800 \mathrm{~kg} / \mathrm{m}^{3}, 800 \mathrm{~kg} / \mathrm{m}^{3}, 1000 \mathrm{~kg} / \mathrm{m}^{3}$. The third version of the wall consists of seven layers with a density of $1000 \mathrm{~kg} / \mathrm{m} 3,800 \mathrm{~kg} / \mathrm{m}^{3}, 600 \mathrm{~kg} / \mathrm{m}^{3}, 500 \mathrm{~kg} / \mathrm{m}^{3}, 500 \mathrm{~kg} / \mathrm{m}^{3}, 500 \mathrm{~kg} /$ $\mathrm{m}^{3}, 500 \mathrm{~kg} / \mathrm{m}^{3}$. The fourth version of the wall consists of seven layers with a density of 500 $\mathrm{kg} / \mathrm{m}^{3}, 500 \mathrm{~kg} / \mathrm{m}^{3}, 800 \mathrm{~kg} / \mathrm{m}^{3}, 1000 \mathrm{~kg} / \mathrm{m}^{3}, 800 \mathrm{~kg} / \mathrm{m}^{3}, 600 \mathrm{~kg} / \mathrm{m}^{3}, 600 \mathrm{~kg} / \mathrm{m}^{3}$. The fifth version of the wall consists of seven layers with the same density of $1000 \mathrm{~kg} / \mathrm{m}^{3}$. The sixth version of the wall consists of seven layers with the same density of $500 \mathrm{~kg} / \mathrm{m}^{3}$.

The data on the coefficients of thermal conductivity and vapor permeability are taken in accordance with the current regulatory document SP 50.13330.2012 "Thermal protection of buildings. Updated edition of regulatory document 23-02-2003". Calculations of the temperature distribution inside the outer wall were carried out according to the method based on one-dimensional stationary thermal conductivity in a homogeneous material of each layer, which is described by the Fourier equation known in engineering practice. Calculations of the partial pressure of water vapor are carried out based on the total resistance to vapor penetration of the outer wall. This resistance consists of the resistance to vapor penetration of all layers of the outer wall and the resistance to moisture exchange on its surfaces.

There is no need to prevent the penetration of rain moisture into the layers of the wall close to the outer surface $[4,5]$ and, therefore, forming them more dense.

\section{Result of research}

The results of calculations of changes in partial pressures at full saturation and at the existing humidity inside the expanded clay concrete block for all 6 variants of the density of the outer wall layers are shown in the graphs (Fig. 2-7).

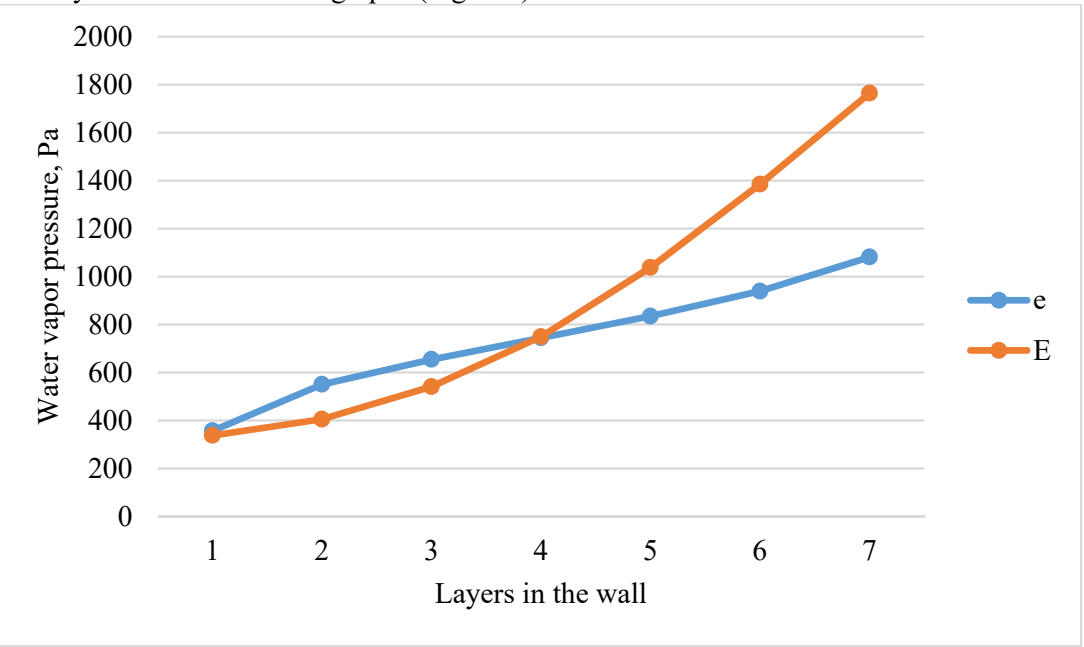

Fig. 2. Change in partial pressures at full saturation (E) and with existing humidity (e) inside the outer wall for option 1 . 


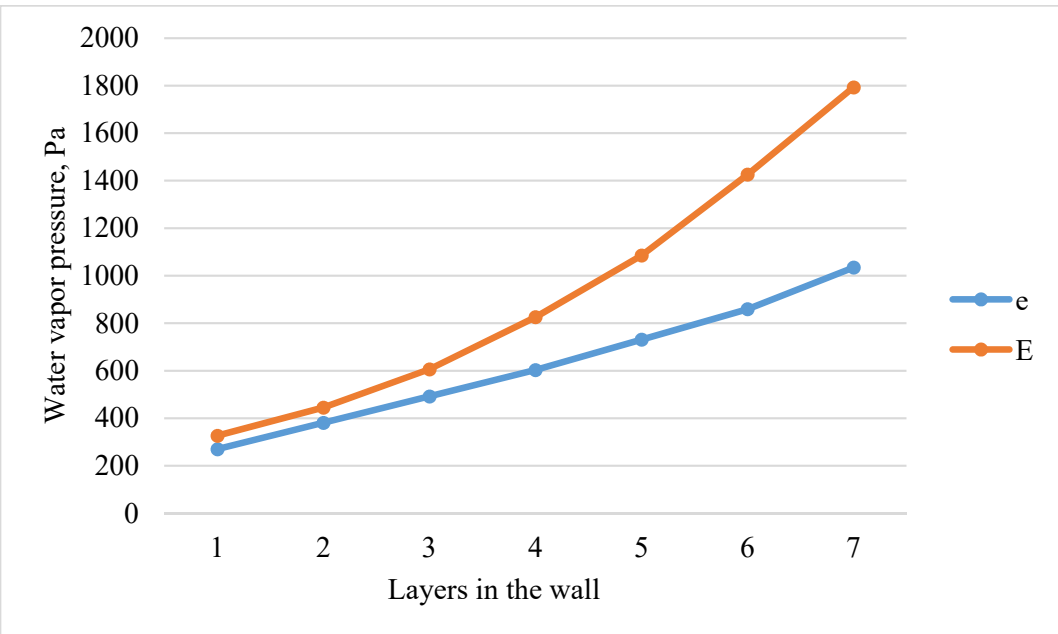

Fig. 3. Change in partial pressures at full saturation (E) and at existing humidity (e) inside the outer wall for option 2 .

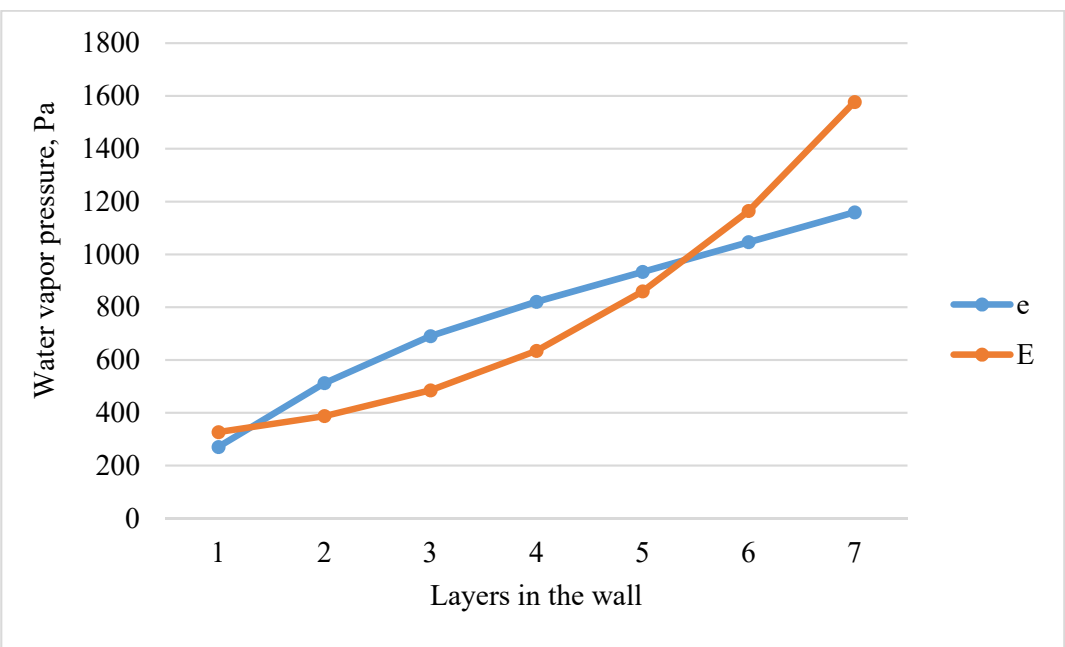

Fig. 4. Change in partial pressures at full saturation (E) and at existing humidity (e) inside the outer wall for option 3 .

The figures show the intersection or non-intersection of the curves of the partial pressure lines at full saturation and at the existing humidity, which allows us to draw conclusions about the quality of the decisions made on the formation of layers of expanded clay concrete with different densities inside the wall.

In fig. 2, 4 (options 1 and 3), it can be seen that the lines of partial pressures at full saturation and at the existing humidity intersect twice, which indicates the condensation of moisture inside the wall in winter, which will freeze and then thaw, destroying the material 
and reducing the durability of the outer walls, which is not acceptable. Such wall options require the use of additional vapor barrier on the inner surfaces of the outer walls.

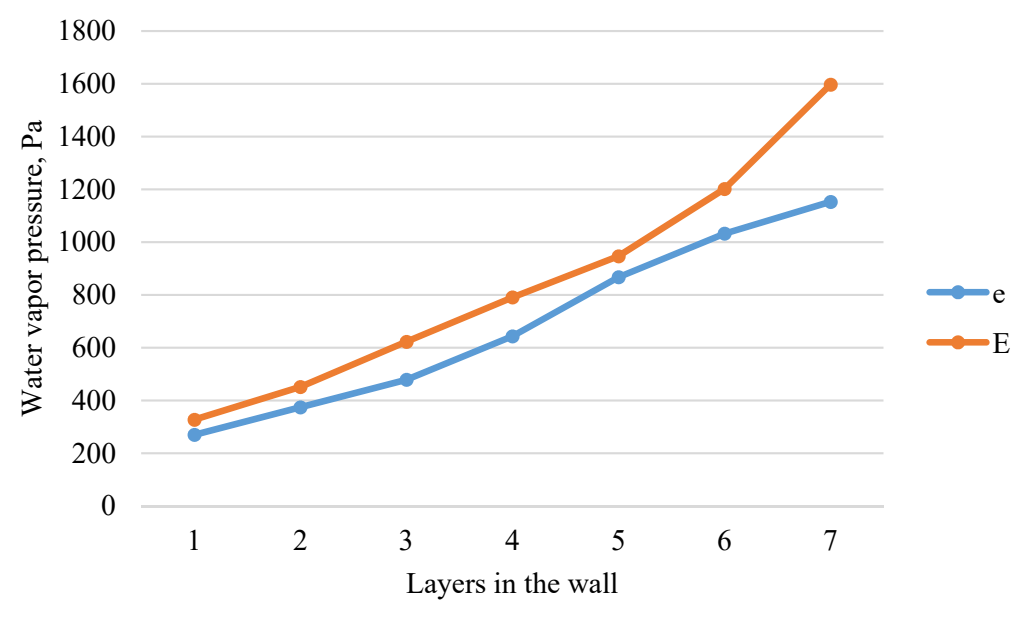

Fig. 5. Change in partial pressures at full saturation (E) and at existing humidity (e) inside the outer wall for option 4 .

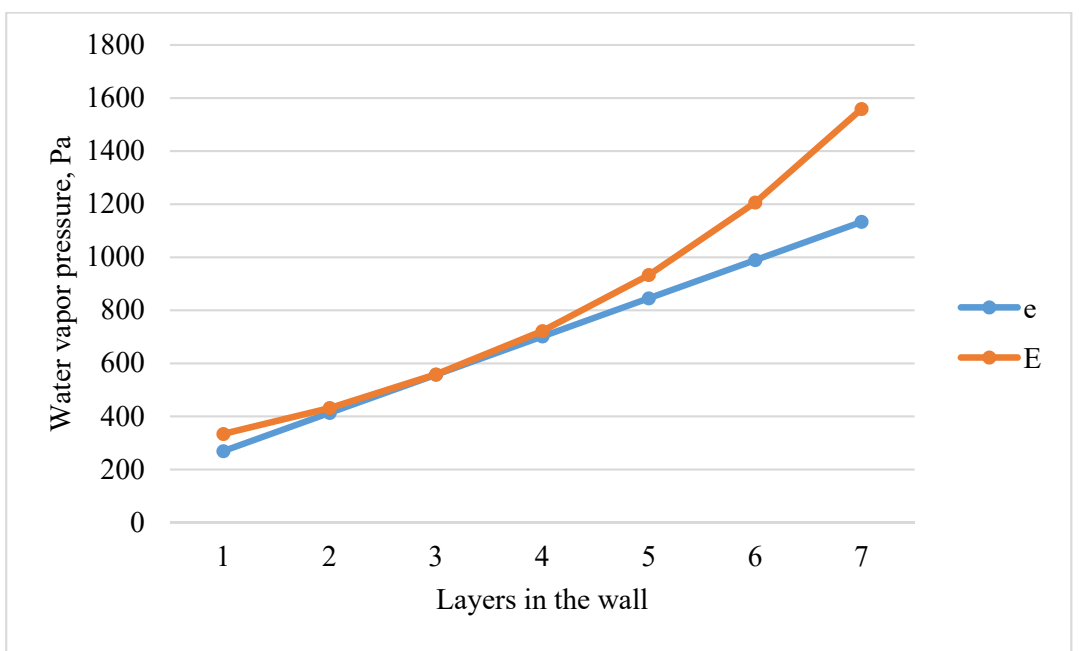

Fig. 6. Change in partial pressures at full saturation (E) and with existing humidity (e) inside the outer wall for option 5 .

With options 2 and 4 (Fig. 3 and 5), the curves of the partial pressure lines at full saturation and at the existing humidity do not intersect, which means that the wall is dry and there is no moisture condensation in it, such a wall can be suitable for use in building.

In fig. 6 and 7 (options 5 and 6), the curves of the partial pressure lines at full saturation and at the existing humidity for a number of layers inside the wall merged together into a 
single line. Which indicates a possible condensation inside the wall and these wall options are also not suitable without additional vapor barrier for the inner surface of the outer walls.

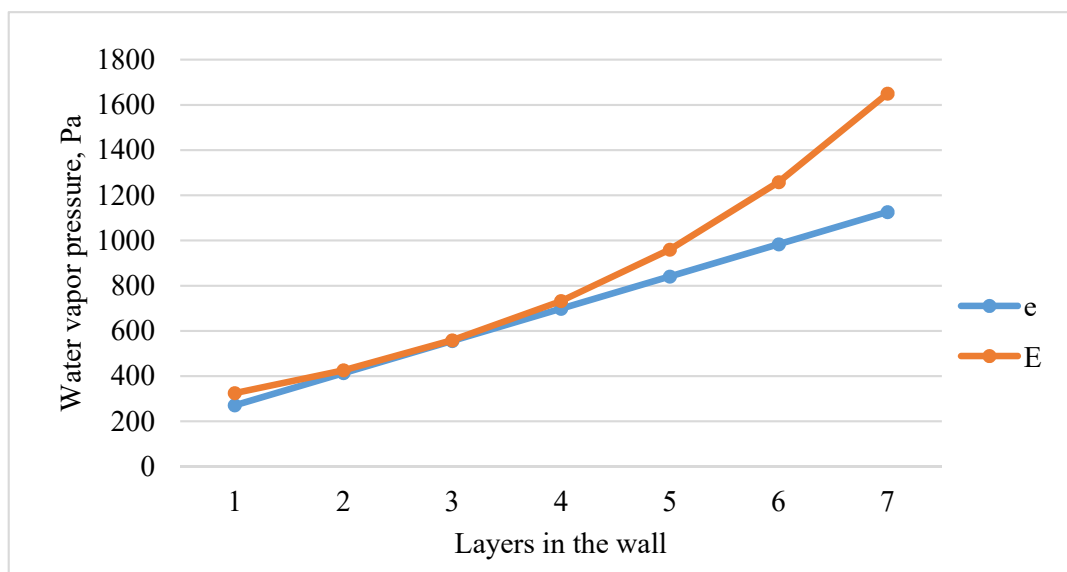

Fig. 7. Change in partial pressures at full saturation (E) and at existing humidity (e) inside the outer wall for option 6 .

In fig. 8 shows, the temperature change inside the wall for options 1,2 and 3 ; on the horizontal axis 3-9 - 7 layers inside the wall, 1, 2 - the temperature on the outer surface and in the outdoor air, 10, 11 - the temperature on the inner surface and in the indoor air.

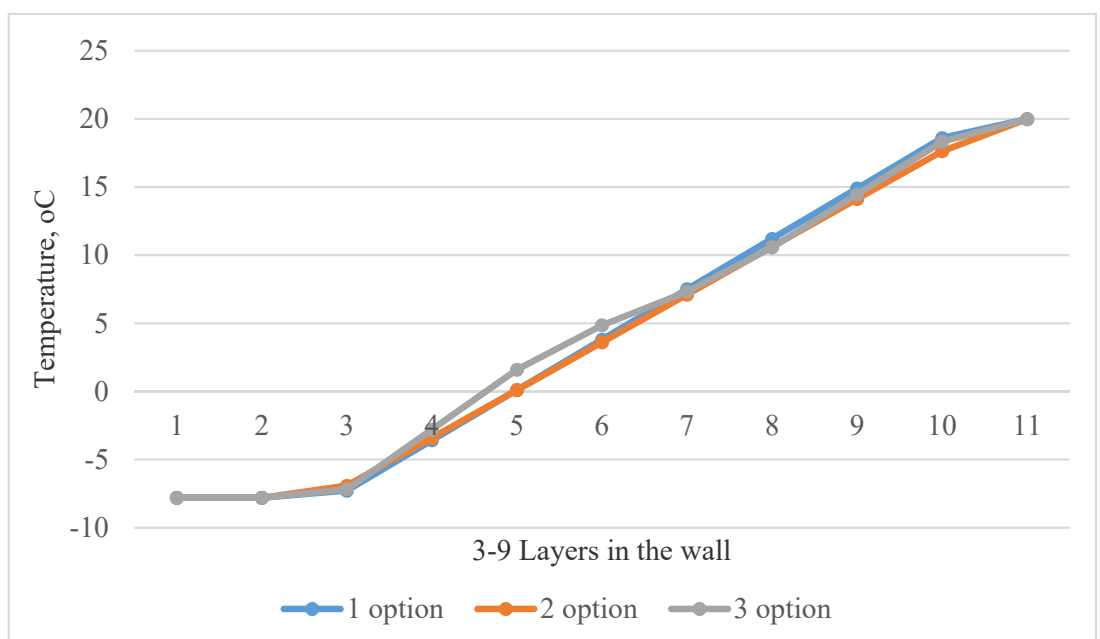

Fig. 8. Change temperature inside the wall for options 1, 2 and 3, where 3-9 - 7 layers inside the wall, 1,2 - the temperature on the outer surface and in the outdoor air, 10, 11 - the temperature on the inner surface and in the indoor air. 
In fig. 9 shows, the temperature change inside the wall for options 4, 5 and 6; on the horizontal axis 3-9 - 7 layers inside the wall, 1,2 - the temperature on the outer surface and in the outdoor air, 10, 11 - the temperature on the inner surface and in the indoor air.

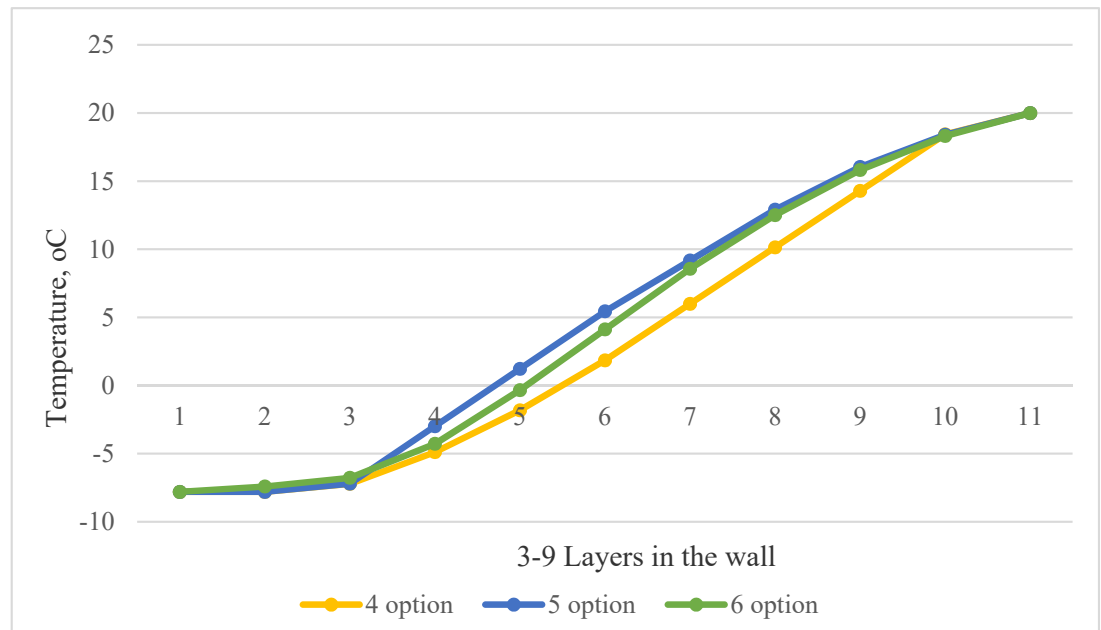

Fig. 9. Change temperature inside the wall for options 4, 5 and 6, where 3-9 - 7 layers inside the wall, 1,2 - the temperature on the outer surface and in the outdoor air, 10, 11 - the temperature on the inner surface and in the indoor air.

In fig. 10 shows, the resistance to heat transfer of the outer wall with 6 considered options for the density of layers inside the wall.

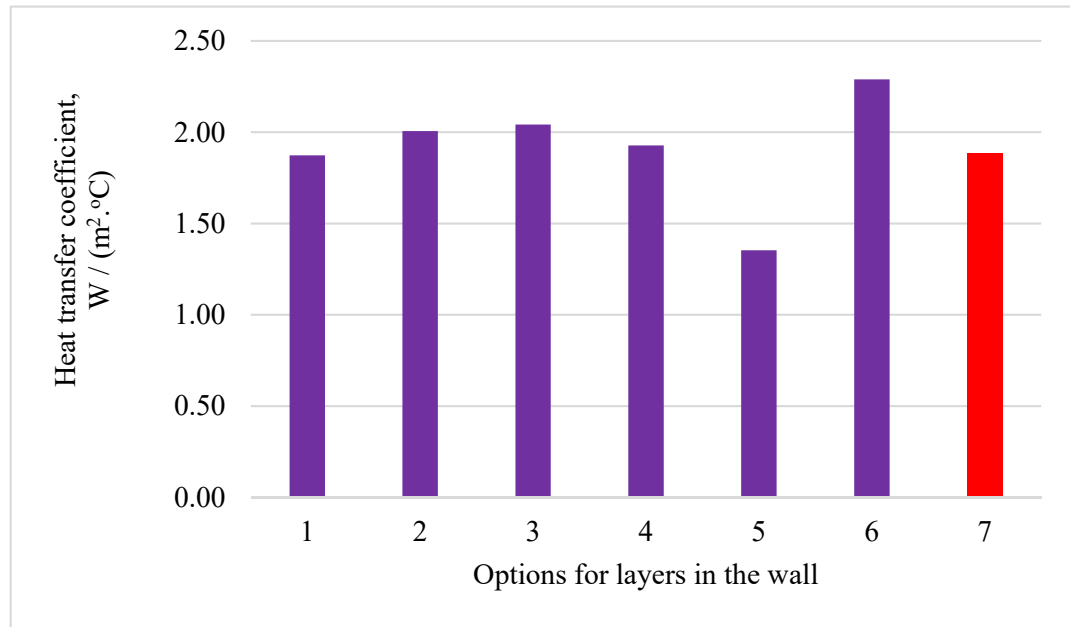

Fig. 10. Change in the resistance to heat transfer of the outer wall with the considered 6 options for the thickness and density of layers in the thickness of the wall, 7 - the standard value of the resistance to heat transfer for the city of Moscow. 
The low moisture content in the layers of blocks increases the resistance to heat transfer of the outer wall, which is useful for solving the problems of energy saving in buildings [6, 7]. The obtained values of the resistance to heat transfer for options 2 and 4 satisfy the requirements of the norms for thermal protection and protection against excessive moisture of the outer walls of buildings [8].

\section{Conclusions}

Layer-by-layer moulding of expanded clay foam concrete blocks allows obtaining blocks for external walls with new properties.

When forming expanded clay concrete blocks in layers, layers can be made with a given density and coefficients of thermal conductivity and vapour permeability.

Of course, you can create an outer wall from layers of different materials, but a single block with a single moulding concept is still better for installing and maintaining the outer walls, since dealing with fewer materials on the construction site is better for increasing construction speed. The durability of a single building material is also higher.

It is possible that it would be possible to form blocks or bricks from other materials also layer by layer, using the layers necessary for the construction of a particular building.

With the right combination of thermal conductivity and vapor permeability coefficients, as well as density and strength properties, it is possible to obtain an outer wall capable of saving energy with low heat loss, capable of being dry in winter, to increase the durability of the building.

\section{References}

1. A.I. Ananiev, A.G. Rymarov, N. A. Denshchikov, Industrial and civil engineering, 1, 28-34 (2021)

2. I. YA. Kiselev, Building materials, 7, 17-18 (2003)

3. S.V. Kornienko, Energy security and energy saving, 4, 12-17 (2015)

4. I.L. Shubin, A.I. Anan'ev, Industrial and civil engineering, 3, 57-59 (2013)

5. O.I. Lobov, A.I. Anan'ev, A.G. Rymarov, Industrial and civil engineering, 11, 67-71 (2016)

6. O.I. Lobov, etc., Urban planning, 4, 61-65 (2010)

7. O. Brukhanov, A. Rymarov, A. Malysheva, D. Titkov, IPICSE 2016, 04028 (2016)

8. A.G. Rymarov, Academia. Architecture and construction, 5, 362-364 (2009) 